\title{
Pyrolysis of Scrap Tyres and Waste Lube Oil by Using Catalytic Agent
}

\author{
IshfaqAbdullah $^{1}$, S. H JavaidNaqvi ${ }^{2,}$ Hafiz Ahmad Bilal $^{3}$, Sana Jamal ${ }^{4}$ \\ ${ }^{1}$ Chemical Engg.Dept, Sharif College of Engineering \& Technology Lahore, Pakistan \\ ${ }^{2}$ Chemical Engg.Dept, University of Engineering \& Technology Lahore, Pakistan \\ ${ }^{3}$ Chemical Engg.Dept, Sharif College of Engineering \& Technology Lahore, Pakistan \\ ${ }^{4}$ Chemical Engg.Dept, Sharif College of Engineering \& Technology Lahore, Pakistan
}

\section{ABSTRACT}

Scrape tyres and waste lube oil are the cause of great environmental issues because they are not biodegradable and their elements cannot be recovered and they are causing great environmental pollution. Secondly, the world needs the new sources of energy due to depletion of oil sources. In this experiment, pyrolysis of scrape tyres alone and pyrolysis of mixture of scrape tyres and used lubricating oil by using catalytic agent $(\mathrm{CaCO} 3)$ is done to see the effect of waste lube oil and catalytic agent on pyrolysis of scrape tyres. The value of products of both samples (scrape tyres alone, mixture of scrape tyres and used lubricating oil) has been studied and compared.

KEY WORDS: Tyres, Lube Oil, Catalytic Pyrolysis, Calcium Carbonate.

\section{INTRODUCTION}

It has been estimated that the total manufacturing of tyres all over the world is more than 1200 million per year, which is a big source of eco problems. How to reuse and dispose of options for tyres has gained the alarming situations now days. However legislation in the form waste landfill has the specific proposal to prohibit the landfilling of tyres. In addition it's also resulting of high cost. Open dumping has also resulted in an environmental pollution. Increase in energy demand, stringent emission norms and depletion of oil resources led the researchers to find alternative fuels for internal combustion engines.

Fore mentioned reasons, recycling of waste rubber has received much attention in recent years all over the world. The present rate of economic growth is unimaginable without saving of fossil energy like crude oil, natural gas or coal.

"Recycling" generally means a process by which we can convert any waste into useful and valuable products rather than disposing them off. Disposing of material by doing landfill causes many environmental issues. Recycling of material help us to reuse material in better and effective way which can not only reduce the problem of environmental pollution but also provider's us good and valuable things at lowest cost by reducing our energy expenditures.

The complicated chemistry of tyres causes a gigantic problem to recycle them. The tyres are chemical bounded by a very complex chemistry of cross linkage, that's why tyres are neither easily disposable nor recyclable. Tyres are mainly consisting of carbon black, many inorganic and organic constituents that make them uneven to recycle them.

Heating of organic compound beyond the certain limits leads to decomposition since its chemical bonds have limited thermal stability. This type of decomposition usually leads to production of smaller molecule, although the resulting fragments and compounds may also linked and form larger compound to the starting molecule. When the heating temperature is above $300-350^{\circ} \mathrm{Cthe}$ chemical processes caused by thermal energy alone are called pyrolysis.

Pyrolysis is generally associated with burning, although the burning is more complex. The main process in burning is typically the combustion, although the other processes including pyrolysis, volatilization, steam distillation etc., are present.

Combustion is an oxidation process (commonly using oxygen), which produces heat and usually generates very small molecules such as $\mathrm{H}_{2} \mathrm{O}, \mathrm{CO}_{2}$, $\mathrm{CO}$, and $\mathrm{N}_{2}$ from the organic compound.

The initiating of burning is caused in many cases by a pyrolysis process. For these reasons, pyrolysis and burning are closely related subjects and pyrolysis can be studied either in inert atmosphere or in presence of a specific level of oxygen mixed in an inert.

Considerable information regarding pyrolysisoftyres is available; howeverstill require much in-depth studies. Pyrolysis is the thermal decomposition of material at higher temperature. Pyrolysis is a process of particular interest to people who are interested in developing alternative fuels. Pyrolysis is a basically irreversible process in which 
both chemical and physical changes occurred. In a great number of industries it is carried out under pressure at high temperature.

Pyrolysis has become the most ecofriendly method to caste away the problem of waste handling. The process is carried out under vacuum system. There are many parameters which have directly influence on the pyrolysis are temperature, pressure, type of apparatus and material used. This results differently. Advantage of Pyrolysis technique is gaining $40-60 \%$ oil, $10-30 \%$ gas, rests is char.

Pyrolysis is the degradation of rubber of the tyres by using heat in the absence of oxygen. The tyres rather than burn, breakdown and result into oil and gas leaving a residue solid. The yield of oil from the process can be high of the order of $60 \%$ and the oil is the liquid it has advantages the ease of handling, storage and transport facility.

Recycling of tyres by the pyrolysis has resulted in ecofriendly process technique. Solid, liquid and gases are products of tyres pyrolysis. Solid product of pyrolysis is 35 to $45 \%$. Pyrolysis solid waste composed of black carbon and different minerals constituents. These solid waste materials can be used again in different industries specially rubber industries as activated carbon. The liquid product is 45 to $65 \%$. Liquid products are organic compounds. This pyrolysis liquid can be used as a fuel. Its gaseous products are 10 to $25 \%$. Pyrolytic gases are mainly the mixture of $\mathrm{CO}, \mathrm{CO}_{2}, \mathrm{H}_{2}, \mathrm{H}_{2} \mathrm{~S}$, and $\mathrm{CH}_{4}$ etc. Pyrolytic gaseous mixture is also a source of fuel.

Objective of this thesis is to see impact of waste lube oil on the extraction of pyrolytic oil from pyrolysis of scrap tyres.

\section{Experimental}

\section{Material and Methods:}

Following activities are done for making of feed, collection of scrape tyres and waste lube, cutting of tyres into the square pieces of approximately 1-2 inch size, removal of dust from pieces, splitting of steel wires from tyres, filtering of waste lube oil. Pyrolysis of waste tyres with catalytic agent is done in equipment. This equipment consisted of furnace chamber, condenser and heater.

*In the 1st batch One $\mathrm{kg}$ pieces of tyres and 0.5 $\mathrm{kg}$ of catalytic agent $\mathrm{CaCO}_{3}$ were weighed and put into the furnace chamber. Then set the equipment and start the procedure. After one hour vapors were absorbed and increased flow rate of water for condenser. Then after few minutes liquid oil was observed at temperature $310^{\circ} \mathrm{C}$. Approximately $600 \mathrm{ml}$ of oil collected. The end product of pyrolysis process was dry carbon residue.

**In second batch repeated the procedure with same parameters, in which 1 liter of waste lube oil was addedwith the scrape tyres and catalytic agent $\mathrm{CaCO}_{3}$ to see the impact of waste lube oil on pyrolysis of scrape tyres. Pyrolysis of scrape tyres and waste lube gave approximately $800 \mathrm{ml}$.

\section{RESULTS AND DISCUSSION}

Effect of temperature and time was absorbed against the sample collected for both batches as shown in the tables. Amount of sample (oil) collected increases with the increase of temperature. For the batch $1 *$ between the range of $300{ }^{\circ} \mathrm{C}$ amount of sample collected was just $50 \mathrm{ml}$, but between the range was $300-400^{\circ} \mathrm{C}$ production of sample oil increases and it was maximum during this temperature range. After $400^{\circ} \mathrm{C}$ it was absorbed that the amount of sample oil gradually decreases as shown in table 1 .

Table 1: Impact of temperature on product yield (Batch 1*)

\begin{tabular}{|l|l|l|l|}
\hline Temp. $\left({ }^{0} \mathrm{C}\right)$ & 300 & 400 & 450 \\
\hline Oil $(\mathrm{ml})$ & 50 & 480 & 600 \\
\hline
\end{tabular}

Table 2: Sample Collected against different time intervals (Batch $1 *$ )

\begin{tabular}{|l|l|}
\hline Time (hrs.) & Oil $(\mathrm{ml})$ \\
\hline 0.5 & 20 \\
\hline 1 & 180 \\
\hline 1.5 & 500 \\
\hline 2 & 600 \\
\hline
\end{tabular}

To see the impact of lube oil on pyrolysis of scrape tyres, pyrolysis of scrape tyres done with waste lube oil. As shown in the table 3 waste lube oil has great impact on pyrolysis product. With same temperature range's and time limits, quantity of pyrolysis product collectedmoreas compare to pyrolysis of scrape tyres alone as shown in table $3 \& 4$.

Table 3: Impact of temperature on product yield: (Batch 2**)

\begin{tabular}{|l|l|l|l|}
\hline Temp. $\left({ }^{\circ} \mathrm{C}\right)$ & 300 & 400 & 450 \\
\hline Oil & 90 & 650 & 800 \\
\hline
\end{tabular}

Table 4: Sample Collected against different time intervals (Batch 2**)

\begin{tabular}{|l|l|}
\hline Time (hrs.) & Oil (ml) \\
\hline 0.5 & 20 \\
\hline 1 & 380 \\
\hline 1.5 & 600 \\
\hline 2 & 800 \\
\hline
\end{tabular}

IV. Comparison of Both Samples 
Int. Journal of Engineering Research and Applications www.ijera.com ISSN : 2248-9622, Vol. 4, Issue 11( Version 1), November 2014, pp.87-90

Ist Batch

Vapor Pressure against Temperature (Volatility):

\begin{tabular}{|l|l|}
\hline Temp. $\left({ }^{\circ} \mathrm{C}\right)$ & Pressure (Barr) \\
\hline 40 & 0.12 \\
\hline 50 & 0.13 \\
\hline 60 & 0.16 \\
\hline 70 & 0.20 \\
\hline 80 & 0.24 \\
\hline
\end{tabular}

Rate of Flow against Different Temperature (Viscosity)

\begin{tabular}{|l|l|}
\hline Temp. $\left({ }^{\mathrm{O}} \mathrm{C}\right)$ & Time $(\mathrm{sec})$ \\
\hline 40 & 18.25 \\
\hline 50 & 16 \\
\hline 55 & 15.04 \\
\hline 60 & 14.09 \\
\hline 70 & 12.01 \\
\hline
\end{tabular}

Flash point: $41^{\circ} \mathrm{C}$

Fire point: $46^{\circ} \mathrm{C}$

Smoke Point:3 inch

\section{Batch}

Vapor Pressure against Temperature (Volatility):

\begin{tabular}{|l|l|}
\hline Temp. $\left({ }^{\circ} \mathrm{C}\right)$ & Pressure (Barr) \\
\hline 40 & 0.10 \\
\hline 50 & 0.11 \\
\hline 60 & 0.13 \\
\hline 70 & 0.18 \\
\hline 80 & 0.22 \\
\hline
\end{tabular}

Rate of Flow against Different Temperature (Viscosity):

\begin{tabular}{|l|l|}
\hline Temp. $\left({ }^{O} \mathrm{C}\right)$ & Time $(\mathrm{sec})$ \\
\hline 40 & 54 \\
\hline 50 & 49 \\
\hline 55 & 43 \\
\hline 60 & 33 \\
\hline 70 & 22 \\
\hline
\end{tabular}

Flash Point: $\quad 46^{\circ} \mathrm{C}$

Fire Point: $\quad 54^{\circ} \mathrm{C}$

Smoke Point:3.6 inch
Oil samples obtained from both batches tested in the lab. Compared results obtained after sampling of both batches. Comparison of results clearly showing the effect of waste lubes oil on pyrolysis of scrape tyres. Product of pyrolysis of scrape tyres with waste lube oil has shown much better results than pyrolysis of scrape tyres alone.

\section{Conclusion}

Pyrolysis of scrape tyres with waste lube oil by using catalyst agent had given much better and improved results as compared to pyrolysis of scrape tyres alone.

\section{Acknowledgements}

The financial support provided by Sharif College of Engineering\& Technology, Lahore and Technical assistance of Universityof Engineering \& Technology, Lahore is gratefully acknowledged.

\section{References}

[1] O.Senneca, P.Salatino, R.Chirone.A Fast heating rate thermogravimetric study of the pyrolysis of the scrap tyres. May 1999.

[2] William PT, Brindle AJ.Fluidised bed pyrolysis and catalytic pyrolysis of scrap tyres. 2003.

[3] Laresgoiti MF, Caballero BM, de Macro I, Torres A, Cabrero MA, Chomon MJ. Characterization of the liquid products obtained in tyre pyrolysis. 2004.

[4] Uçar S, Karagöz S, Yanik J, Saglam M, Yuksel M. Copyrolysis of scrap tires wit waste lubricant oil. 2005.

[5] Ucar S, Karagoz S, Ozkan AR, Yanik J. Evaluation of two different scrap tyres as hydrocarbon source by pyrolysis. 2005.

[6] Lam SS, Russell AD, Chase HA. Pyrolysis using microwave heating: asustainable process for recycling used car engine oil. 2010.

[7] Manar E. Abdul-Rauf, NermineE.Maysour, Abdul-Azim, A. Abdul-Azim,

MahasenS.Amin. Thermochemical recycling of mixture of scrap tyres and waste lubricating oil into high caloric value products. 2010.

[8] M.Rofiqul Islam, M.Parveen, H.Haniu and M.R.IslamSarkar.Innovation in pyrolysis Technology For Management of scrap tyre: a Solution of Energy and Enviornment. 2010.

[9] Su.ShiungLum, Alan.D.Russel, ChernLeing Lee, Howard.Microwave pyrolysis, a novel process for recycling waste automotive engine oil. April 2010. 
Int. Journal of Engineering Research and Applications www.ijera.com ISSN : 2248-9622, Vol. 4, Issue 11( Version 1), November 2014, pp.87-90

[10] Martin Bajus, Natalia Olahova. Thermal Conversion of Scrap Tyres.

[11] Jasmine shah, M.Rasul Jan,

FazalMabood.Catalytic Pyrolysis of Waste

Type Rubber into HydrocorbonsVia Base Catalysts.

[12] A.M. Fernandez, C.Barriocanal, R.Alvarez. Pyrolysis of a waste tyres from the grinding of scrap tyres. December 2011.

[13] Marek.A.Wojtowics,

MachealA.Serio.Pyrolysis of scrap tyres:

Can it be profitable?

[14] Wisa.Manasomboonphan, Suwannee Junyapoon.Production of liquid fuel from waste lube oil used by pyrolysis process. 2012. 